\title{
APRENDIZAGEM ATIVA NA FORMAÇÃO CONTINUADA DOCENTE: RELATOS DE EXPERIÊNCIAS
}

\section{ACTIVE LEARNING IN TEACHER PROFESSIONAL DEVELOPMENT: EXPERIENTIAL REPORTS}

\author{
Marize Lyra Silva PASSOS ${ }^{1}$ \\ Isaura Alcina Martins NOBRE ${ }^{2}$ \\ Jaqueline MAISSIAT ${ }^{3}$
}

RESUMO: Este trabalho faz um breve relato da experiência da aplicação de abordagens pedagógicas baseadas na aprendizagem ativa e centrada no aluno, com ênfase em métodos colaborativos em curso de formação inicial e continuada para professores. Esse curso foi intitulado "Oficina de Aprendizagem Ativa: a experiência finlandesa de educação centrada no aluno". Ele é resultado do trabalho de desenvolvimento realizado durante a fase final do curso "VET Teachers for the Future - Professional Development Certificate - Cohort III", realizado pela Häme University of Applied Sciences $\left(\mathrm{HAMK}^{5}\right.$ ) na cidade de Hämeenlinna, Finlândia, o qual ocorreu durante três meses no ano de 2016. Foi possível perceber durante a realização desta oficina piloto que o modelo proposto foi bem aceito pelos cursistas e que ele trouxe resultados concretos de aprendizagem. Estes resultados incentivaram os professores a ofertarem novas oficinas.

PALAVRAS-CHAVE: Formação de professores. Aprendizagem ativa. Uso de tecnologias.

ABSTRACT: This report presents some experiences concerning the application of approaches based on active learning, with emphasis on collaborative methods in a professional development course for teachers. Entitled "The Active Learning Workshop: The Finnish experience of student-centered education" was the development project outcome of the final phase required by the "VET Teachers for the Future - Professional Development Certificate - Cohort III" course at HAMK (University of Applied Sciences) in the city of Hämeenlinna in Finland, which took place during three months in 2016. It was possible to realize during this pilot workshop, that the proposed model was well accepted by the students and that it brought concrete learning results. These results encouraged teachers to offer other workshops.

KEYWORDS: Teacher training. Active learning. Use of technologies.

\footnotetext{
${ }^{1}$ Instituto Federal do Espírito Santo (IFES), Vitória - ES - Brasil. E-mail: marize@ifes.edu.br.

${ }^{2}$ Instituto Federal do Espírito Santo (IFES), Vitória - ES - Brasil. E-mail: isaura@ifes.edu.br.

3 Instituto Federal do Espírito Santo (IFES), Vitória - ES - Brasil. E-mail: jaqueline.maissiat@ifes.edu.br.

${ }^{4}$ Curso financiado pela Chamada Pública CNPq - SETEC/MEC No 026/2015 - Programa Professores para o Futuro (Finlândia) III.

${ }^{5}$ Disponível em: <http://www.hamk.fi/english/Sivut/default.aspx>. Acesso em: 10 jun. 2017.
} 


\section{Introdução}

Os alunos do século XXI já não possuem o mesmo perfil dos alunos do século passado; neste novo contexto, a escola continua tendo um papel fundamental para o apoio na construção do conhecimento humano e, para tal, precisamos ter educadores com uma nova visão do papel da educação para o novo século, uma vez que os estudantes de hoje estão crescendo em um mundo que é muito diferente do mundo de seus pais, avós e de nossos educadores.

Neste novo contexto a aprendizagem ativa e centrada no aluno vem recebendo uma considerável atenção, e muitas vezes é apresentada ou percebida como uma mudança radical da instrução tradicional, tema que frequentemente polariza o corpo docente. A aprendizagem ativa atraiu fortes defensores entre alguns professores, que procuravam alternativas aos métodos de ensino tradicionais, enquanto os professores céticos consideram a aprendizagem ativa como mais uma abordagem em uma longa linha de educação.

Aliado a isso e à demanda por novas habilidades para atuarem na educação do século XXI, vê-se a importância dada à necessidade da formação continuada dos professores. A partir da realização de cursos, é possível ao docente estabelecer relações entre teoria e prática, ou seja, ser capaz de buscar na teoria elementos para possíveis contextualizações, ressignificando sua prática, com base em uma ação reflexiva da sua experiência docente. Freire (1996. p. 18) afirma que: “[...] na formação permanente dos professores, o momento fundamental é o da reflexão crítica sobre a prática”.

Entretanto, para muitos professores permanecem questionamentos sobre o que é a aprendizagem ativa centrada no aluno, como ela difere da educação tradicional e como utilizá-la em sala de aula. Muitas destas questões ficam mais claras quando se vivencia uma experiência de aprendizagem em um ambiente de ensino centrado no aluno.

Visando responder a estas questões e proporcionar a oportunidade desta vivência foi proposta a realização, pelo Centro de Referência em Formação e em Educação a Distância (Cefor) do Instituto Federal do Espírito Santo (Ifes), um curso intitulado Oficina de Aprendizagem Ativa: a experiência finlandesa de educação centrada no aluno. Esse curso fez parte da fase final do curso VET Teachers for the Future - Professional Development Certificate - Cohort III (VET III). Esta oficina foi planejada baseada nos princípios da aprendizagem ativa e teve como base a experiência vivida, por uma das pesquisadoras, durante a realização do curso VET III na Häme University of Applied Sciences durante 
três meses do ano de 2016.

\section{Planejamento e Execução da Oficina}

O curso utilizou tópicos e metodologias que foram apendidos durante o programa VET III. A seguir, no Quadro 1, será feita uma breve descrição referente aos objetivos de aprendizagem, atividades realizadas e materiais utilizados para a execução dos três dias de oficina.

Quadro 1: Planejamento da oficina.

\begin{tabular}{|c|c|c|}
\hline \multicolumn{3}{|c|}{ Dia 1} \\
\hline Objetivos & Atividades Realizadas & Materiais \\
\hline 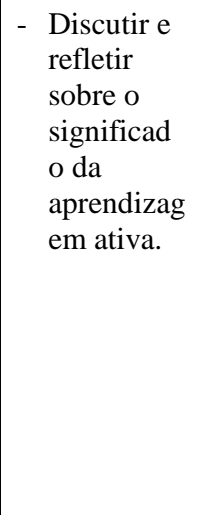 & $\begin{array}{l}\text { Manhã } \\
\text { - Apresentação do programa VET III; } \\
\text { - Apresentação da equipe; } \\
\text { - Quebra-gelo - técnica da caixa surpresa; } \\
\text { - Uso do jogo Following the Finn para instigar os cursistas sobre o } \\
\text { tema aprendizagem ativa. } \\
\text { Tarde } \\
\text { - Criação de grupos de trabalhos - busca pelos pares utilizando } \\
\text { músicas diferentes. } \\
\text { - Utilizar a técnica do Learning Cafe - construção de conceitos sobre: } \\
\text { Individualização; Compartilhamento de responsabilidade; Trabalho } \\
\text { colaborativo; Aprendizagem ativa; Aprender fazendo; } \\
\text { - Discutir em grupo os resultados produzidos no Learning Café e } \\
\text { registrar os resultados em ambientes digitais. }\end{array}$ & $\begin{array}{l}\text { - Vídeo sobre o } \\
\text { programa VET III; } \\
\text { - Jogo Following the } \\
\text { Finn; } \\
\text { - Canetas coloridas; } \\
\text { - Folha de papel A0 ou } \\
\text { cartolina branca. } \\
\text { - Criação de um blog, } \\
\text { grupo de whatsapp e } \\
\text { Facebook para } \\
\text { registro das } \\
\text { demonstrações de } \\
\text { resultados. }\end{array}$ \\
\hline \multicolumn{3}{|c|}{ Dia 2} \\
\hline Objetivos & Atividades Realizadas & Materiais \\
\hline $\begin{array}{l}\text { Discutir e } \\
\text { refletir } \\
\text { sobre } \\
\text { aprendizag } \\
\text { em } \\
\text { centrada } \\
\text { no aluno; } \\
\text { - Planejar } \\
\text { uma } \\
\text { atividade } \\
\text { de sala de } \\
\text { aula } \\
\text { centrada } \\
\text { no aluno. }\end{array}$ & $\begin{array}{l}\text { Manhã } \\
\text { - Realizar uma avaliação inicial sobre o tema aprendizagem centrada } \\
\text { no aluno utilizando o aplicativo Padlet; } \\
\text { - Realizar uma técnica de Brainstorm - técnica das } 100 \text { ideias para } \\
\text { propor o desenvolvimento de uma aula centrada no aluno (activing } \\
\text { learning); } \\
\text { - Cada grupo deve selecionar três ideias. } \\
\text { Tarde } \\
\text { - Propor o planejamento e operacionalização de uma das três ideias; } \\
\text { - Discutir em grupo os resultados do planejamento da aula. }\end{array}$ & $\begin{array}{l}\text { - Criar um Padlet para } \\
\text { ser utilizado pelos } \\
\text { alunos; } \\
\text { - Folha de papel A4; } \\
\text { - Caneta; } \\
\text { - Canetas coloridas; } \\
\text { - Folha de papel A0 ou } \\
\text { cartolina branca. }\end{array}$ \\
\hline \multicolumn{3}{|c|}{ Dia 3} \\
\hline Objetivos & Atividades Realizadas & Materiais \\
\hline $\begin{array}{l}\text { - Discutir e } \\
\text { refletir } \\
\text { sobre } \\
\text { avaliação }\end{array}$ & $\begin{array}{l}\text { Manhã } \\
\text { - Levar o grupo a refletir sobre as diferenças entre o ensino centrado } \\
\text { no professor e centrado no aluno; } \\
\text { - } \quad \text { Realizar uma avaliação inicial sobre o tema avaliação formativa }\end{array}$ & $\begin{array}{l}\text { - Clip Another Brick in } \\
\text { the Wall; } \\
\text { - Vídeo sobre o projeto } \\
\text { Âncora; }\end{array}$ \\
\hline
\end{tabular}




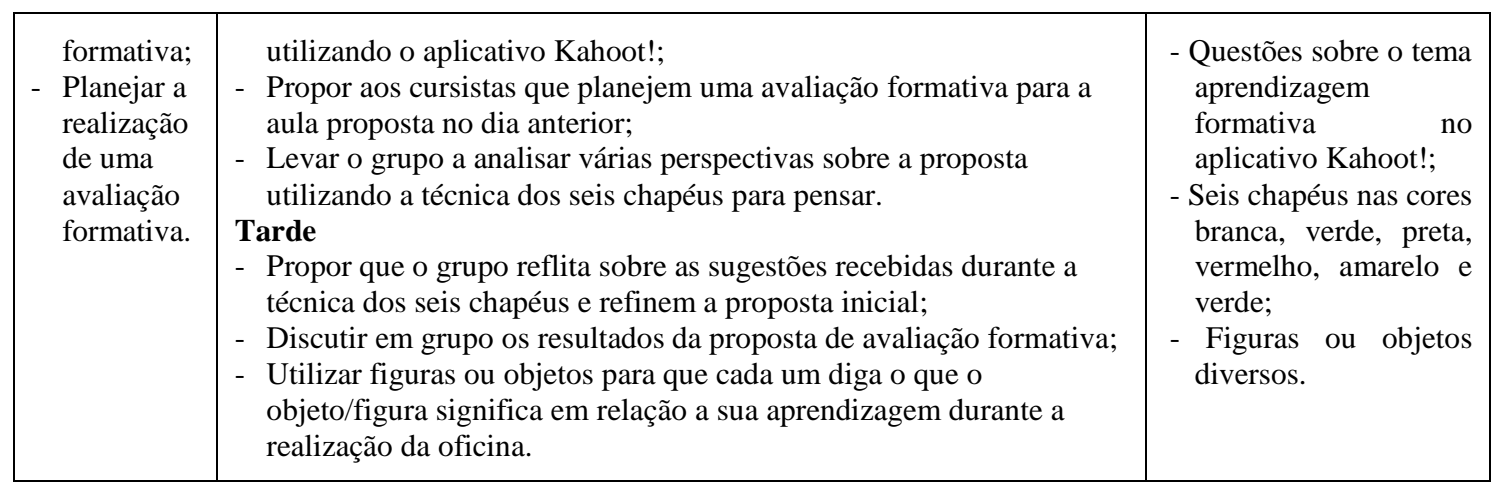

Fonte: autores

A oficina baseou-se em ações práticas que permitiram a conexão entre a teoria e a prática, tornando-a dinâmica e valorizando os conhecimentos prévios dos cursistas, que trabalharam de forma colaborativa. As discussões giraram em torno de problemas do cotidiano de sala de aula, e os cursistas aprenderam uns com os outros, na interação social, que na perspectiva vygostkyana é o veículo fundamental para a transmissão dinâmica do conhecimento social, histórico e cultural. Esta interação implica em certo grau de reciprocidade e bidirecionalidade, ou seja, a interação social supõe envolvimento ativo de ambos os participantes (MOREIRA, 2011). Além do foco na aprendizagem colaborativa, foi também explorado o incentivo à criatividade, principalmente com as atividades de brainstorming, que proporcionam um ambiente de aprendizagem significativa em uma atmosfera relaxada (UNIN; BEARING, 2016).

$\mathrm{Na}$ oficina também foram utilizadas diversas ferramentas digitais que surgem "[...] como instrumentos para serem usados livre e criativamente por professores e alunos" (PONTE, 200, p. 64). Elas possibilitaram a criação de espaços de interação e comunicação, pelas possibilidades alternativas que fornecem de expressão criativa, de realização de projetos e de reflexão crítica, tornando a aprendizagem mais significativa e ativa.

A oficina foi realizada no período de 21 a 23 de novembro de 2016 no Cefor/Ifes, e teve como objetivo permitir aos professores refletirem sobre a aprendizagem ativa a partir de sua vivência na oficina. A aprendizagem centrada no aluno tem como foco conectar a sala de aula e os alunos à vida; nela o professor é considerado um orientador "Coaching", ajudando e orientando os alunos a atingirem os objetivos propostos pelos alunos e pelo professor, e encorajar os estudantes a assumirem um papel ativo no processo de aprendizagem (OVERBY, 2011; UNIN; BEARING, 2016). 


\section{Percepção dos Cursistas sobre a Oficina}

Ao final da oficina os cursistas respondessem a um questionário sobre a sua percepção sobre a oficina. Como resultado foi possível verificar que para os participantes, os conhecimentos adquiridos durante a oficina são: indispensáveis $(72,7 \%)$ ou de contribuição importante $(27,3 \%)$ para a sua prática docente. Os cursistas também fizeram alguns depoimentos espontâneos, como os descritos a seguir, que demonstram que vivenciar a aprendizagem ativa foi um diferencial em seu processo de aprendizagem.

"A oficina oportunizou momentos extremamente alegres, desafiadores enfim, de muito aprendizado. O diferente faz a diferença! Sair do nosso lugar de conforto é necessário! ”

"Gostei muito da Oficina, especialmente por nos expor à metodologia ativa de aprendizagem. Experiências vividas tomamse, muitas vezes, inesqueciveis"

A Oficina ofereceu uma oportunidade ímpar de reflexão e de construção de um fazer pedagógico e de uma práxis muito mais consciente, responsável e feliz”.

\section{Conclusão}

O fato da abordagem de aprendizagem ativa promover um processo de aprendizagem por meio de um método indutivo, fez com que a construção de conhecimento acontecesse de maneira colaborativa e motivadora, onde os cursistas tiveram uma participação ativa a partir de suas experiências e expectativas, tornando o processo de aprendizagem para além do "aprender fazendo", pois a aprendizagem é potencializada por elementos que estimulam processos cognitivos, criativos e emocionais. $O$ uso de tecnologias digitais facilitou a realização de diferentes registros sobre a construção do conhecimento e possibilitou as trocas para a efetiva aprendizagem em rede, mesmo após o encerramento da oficina.

Ao final do processo e de acordo com os resultados obtidos, o grupo de professores que realizou esta oficina ofertou no ano de 2017 cinco novas oficinais nos mesmos moldes da oficina piloto, com novos temas: aprendizagem centrada no aluno, uso de recursos digitais para o século XXI, interdisciplinaridade e avaliação formativa. Além disso, estão fechando para o ano de 2018 um curso de aperfeiçoamento semipresencial seguindo os mesmos moldes do anterior. 


\section{REFERÊNCIAS}

FREIRE, P. Pedagogia da autonomia: saberes necessários à prática educativa. 25. ed. São Paulo: Paz e Terra (Coleção Leitura), 1996.

MOREIRA, M. A. Teorias da aprendizagem. São Paulo: EPU, 2ª ed. 2011.

OVERBY, K. Student-centered learning. ESSAI, v. 9, n. 1, p. 32, 2011.

PONTE, J. P. Tecnologias de informação e comunicação na formação de professores: que desafios?. Revista Iberoamericana de educación, p. 63-90, 2000.

UNIN, N.; BEARING, P. Brainstorming as a Way to Approach Student-centered Learning in the ESL Classroom. Procedia-Social and Behavioral Sciences, v. 224, p. 605-612, 2016.

\section{Como referenciar este relato de experiência:}

PASSOS, Marize Lyra Silva.; NOBRE, Isaura Alcina Martins.; MAISSIAT, Jaqueline. Aprendizagem ativa na formação continuada docente: relatos de experiências. Revista Ibero-Americana de Estudos em Educação, Araraquara, v. 13, n. esp1, p. 540-545, 2017. E-ISSN: 1982-5587. DOI: 10.21723/riaee.nesp1.v13.2018.11450

Submetido em: 30/10/2017

Aprovado em: 01/01/2018 